\title{
UNIVERSITETET I AGDERS RØTTER ER 175 ÅR I 2014 - ANDREAS FAYE OG HOLT SEMINAR
}

\author{
ERNST HÅKON JAHR
}

I år er det 175 år siden Holt seminar, eller Christianssand Stiftsseminarium på Holt ved Tvedestrand starta sin virksomhet. Sokneprest til Holt, Andreas Faye, blei i 1839 gitt i oppdrag å organisere og styre institusjonen. Holt seminar utvikla seg gjennom åra til Kristiansand lærerhøgskole, som var den eldste av de seks utdanningsinstitusjonene som i 1994 gikk inn i den da nye Høgskolen i Agder, og som i 2007 blei til Universitetet i Agder (UiA). Universitetets vogge stod i Holt, og det er altså 175 år siden i år.

For lærerseminaret var det svært heldig at sokneprest Andreas Faye blei dets første bestyrer, eller rektor, som vi ville si i dag. Faye var i samtida kjent som en sentral aktør på ei rekke områder i samfunnet: lokal og nasjonal politiker, formannsskapsmedlem, varaordfører og ordfører, stortingsmann, folkeminnegransker, allmennhistoriker og kirkehistoriker, lærer og teoretisk pedagog, grunnlegger av ei lang rekke institusjoner og organisasjoner, biograf og samfunnsdebattant lokalt og nasjonalt - og prest. Han var aktiv lokalt og nasjonalt, han hadde et imponerende internasjonalt faglig nettverk, en ubendig virketrang og en arbeidskapasitet det gikk frasagn om.

Andreas Faye blei født i Drammen 1802, vokste opp og gikk på den lærde skolen der. I 1823 blei han dimittert til universitetet, der han blei uteksaminert som teolog i 1828. Det sies at flere prestekall da stod ledige, men han valgte likevel å ta imot ei lærerstilling ved Arendal Middelskole. Det betydde nok mye at han i Arendal kom ganske nær Nes Jernverk, der verkseier Jacob Aall (17731844) hadde et velfylt og spennende bibliotek (Eide 2012). Familiene Faye og 
Aall kjente hverandre godt, og Andreas hadde bes $\varnothing \mathrm{kt}$ Nes Jernverk allerede første gang da han var 18 år.

Det er viktig å påpeke at Arendal rundt 1830 hadde et rikt faglig og kulturelt miljø. Byen var på flere måter et akademisk senter. Det var ikke bare viktig i regionen, men var også nasjonalt betydningsfullt. Det var her byfogd Nicolai Henrich Jæger (1780-1846) grunnla studiet av nederlandsk språk i Norge, for bare å nevne én som utmerka seg vitenskapelig i miljøet (Askedal 2011). I 1830-åra hadde Arendal sitt eget trykkeri (N.C. Halds Bogtrykkerie, se Johansen 2012). Det som var et av de første provinstrykkeriene i landet. Byen Arendal hadde opplagt mer å tilby en akademisk og forskningsinteressert teolog enn det et avsides prestekall hadde. Faye var lærer ved middelskolen i Arendal fra 1829 til 1833, da han blei sokneprest i Holt.

Høsten før han begynte som lærer i Arendal, foretok han ei viktig reise til København, med $\varnothing$ konomisk hjelp av Jacob Aall. I København møtte han historiker og biskop (fra 1830) Peter Erasmus Møller (1776-1834). Møller oppfordra Faye til å samle og utgi norske sagn, slik det alt var gjort i Tyskland (av Jacob Grimm) og Danmark (av Just Mathias Thiele). Nå trengtes ei tilsvarende samling fra Norge, mente Møller, slik at en kunne gjøre mer generelle europeiske sammenligninger. Allerede ved denne første utenlandsreisa, 25 år gammel, blei Faye inkludert i et internasjonalt forskernettverk. Dette nettverket holdt han seinere ikke bare ved like, han utvida det også. Faye var i det hele tatt langt mer enn de fleste norske forskere i samtida med i internasjonale forskningssammenhenger.

Det første besøket i København (1828) stimulerte Fayes interesse for sagn og historie. Først vendte han seg mot historia. Allerede 1831 hadde han ferdig verket Norges Historie til Brug ved Ungdommens Underviisning (Faye 1831), den første fullstendige framstillinga av hele Norges historie, også dansketida. Denne boka kom i flere utgaver og opplag, og blei også oversatt til svensk og tysk. Ei sterkt forkorta utgave av denne boka til bruk i skolene kom i mange opplag.

Det samme året, 1831, drog han på ei lengre reise rundt i Europa. Han besøkte Danmark, Tyskland, Sveits, Italia og Frankrike. Overalt studere han historie, filosofi og skolevesen. I Berlin hørte han forelesninger bl.a. av filosofen og teologen Friedrich Schleiermacher (1768-1834), og ellers knytta han direkte personlig kontakt bl.a. med dikterne Adam Oehlenschläger (1779-1850) og H.C. Andersen (1805-1875), med maleren J.C. Dahl (1788-1857) og med sjølveste Johann Wolfgang von Goethe (1749-1832). Etter at Faye hadde vært hos han, omtalte Goethe besøket svært positivt i dagboka si. På denne reisa mottok Faye sterke og fruktbare inntrykk på ei rekke felter, ikke minst av den romantiske filosofien i Tyskland. Når vi tar i betraktning samtidas kommunikasjonsmuligheter, var det internasjonale nettverket Faye hadde opparbeida seg før fylte 30 år, direkte imponerende. 
29 år gammel blei han medlem av Det Kongelige Norske Videnskabers Selskab. Det var i 1832. Det var Selskabets sekretær, poeten og juristen Conrad Nicolai Schwach (1793-1860), som stod bak innvalget. Schwach kjente til Faye fra Arendal, der Schwach var sakfører før han fikk et dommerembete i Trondheim. Grunnlaget for innvalget i Selskabet var Fayes bok Norges Historie (Faye 1831), som jeg nettopp har nevnt.

Vel hjemme igjen etter reisa i Europa i 1832 kasta Faye seg fullt og helt over oppgava med å samle lokale norske sagn. Biskop Møller hadde inspirert Faye med muligheten til å bidra til en felles europeisk sammenligning av landenes sagn og fortellinger.

Fayes innsamlingsarbeid resulterte i samlinga Norske Sagn (Faye 1833). Ei ny utgave av boka, med tittelen Norske Folke-Sagn, utkom 1844, gjenopptrykt i 1948. Faye definerte oppgava si som sagnsamler på denne måten: „En Sagnsamler er at ligne med en Botanicus, der viden om samler Planterne, nedtegner hvor han fandt dem og opbevarer dem saadansom han fandt dem" (Braadland 2004: 9, se også Lindtveit 1961: 48).

Boka Norske Sagn blei utgitt på det lokale trykkeriet i Arendal. Det var et vitenskapelig verk, og både $\mathrm{i}$ forskningsmessig og filosofisk tilnærming til sagnmaterialet er Faye med dette utvilsomt grunnleggeren av moderne folkeminnevitenskap i Norge. Med han som formidler av den tyske romantikken kom „det nasjonale gjennombrudd” i Norge. At det skjedde på Agder, i Arendal og på Holt, var det imidlertid ikke alle som likte i hovedstaden. Der var det det ensidig nasjonale som mest opptok dem, og som de ønska bidrag til.

Andreas Fayes forskningsfeller var imidlertid ikke først og fremst i Kristiania og ved Det Kongelige Frederiks Universitet. Der holdt isteden elevene hans til, og det var P.A. Munch (1810-63), Jørgen Moe (1813-82) og Peter Christen Asbjørnsen (1812-85). Faye var i motsetning til disse tre primært orientert internasjonalt, og han brevveksla med Oehlenschläger i Danmark og Jacob Grimm i Tyskland, han var stimulert til folkeminnearbeid av biskop Peter Erasmus Møller i København, han blei omtalt i positive ordelag i dagboka til Goethe, og han var allerede, som 29-åring, medlem av Videnskabsselskabet i Trondheim. Andreas Faye hadde utvilsomt nådd langt $\mathrm{i}$ ung alder.

Da Fayes Norske Sagn kom ut, anmeldte den 23 år gamle P.A. Munch boka i tidsskriftet Vidar, der han sjøl var redaktør. Denne anmeldelsen (Munch 1833), som var anonym, er blitt karakterisert som et av de verste slakt i vår akademiske historie. Ikke var Fayes Norske Sagn ei samling med kilder til Norges eldste historie - det ønska Munch at den skulle ha vært -, den brakte heller ikke sagna i riktig språklig stil. Munch savna det som seinere er blitt kalt ,den norske stemmen”, dvs. slik Asbjørnsen og Moes eventyr framstod språklig ti år seinere.

Faye sjøl brydde seg først ikke om denne anmeldelsen. Den var for det første anonym. Dessuten var det mange feilaktige påstander i den, og den anonyme 
anmelderen hadde ikke fått med seg at boka var et vitenskapelig verk, og ment som et bidrag til et felleseuropeisk forskningsprosjekt. Munch tolka Norske Sagn isteden som mislykka skjønnlitteratur. Først da Faye fikk vite at det var P.A. Munch som stod bak, fant han å måtte skrive et svar. Det kom over to numre av tidsskriftet (Faye 1833b).

Munch var altså sjøl redaktør av tidsskriftet Vidar, for $\emptyset$ vrig sammen med dikteren Johan Sebastian Welhaven (1807-73). Andre sagn-interesserte utover landet var svært opprørte på Fayes vegne over Munchs totalt negative omtale. Dikterpresten Simon Olaus Wolff (1796-1859) skreiv et kraftig svar på Munchs anmeldelse, men fikk det refusert av redaktørene i Vidar, altså, må vi tro, bl.a. av Munch sjøl. Wolffs innlegg (Wolff 1833) kom isteden på trykk i avisa Den vestlandske Tidende i Arendal, ei avis Andreas Faye hadde vært med på å starte (Lindtveit 1961: 14). Men dermed forblei dette viktige svaret ukjent for de toneangivende kretser i hovedstanden. Det var nok få der som leste provinsaviser som Den vestlandske Tidende.

En annen viktig aktør, som i det skjulte virka mot Faye, var ingen ringere enn den unge Jørgen Moe. Han var ute etter å skaffe seg et navn, hevder professor Arne Bugge Amundsen ved Universitetet i Oslo (Amundsen 2002), og Bugge Amundsen kaller rett ut Moe en „muldvarp” i sitt forhold til Faye. Faye hjalp sin yngre kollega, altså Jørgen Moe, til en huslærerpost ved Nes Jernverk, og ansikt til ansikt med Faye var Moe positiv og nærmest krypende. Men i brev til folk i Kristiania forsøkte Moe å latterliggjøring Faye, spesielt som sagnsamler. (Se Krogvig 1915.)

Det var vel slik at P. A. Munch og Jørgen Moe på denne tida begge arbeida med å skape egne revir, egne områder. Munch ønska å etablere historie som eget fag. Historiefaget skulle drives av egne eksperter, av faghistorikere. Og Jørgen Moe emna på egne sagn- og eventyrutgivelser, som vi vet. Faye var åtte år eldre enn Munch og elleve år eldre enn Moe, og de to så begge på den arendalbaserte Andreas Faye som en viktig konkurrent. Begge følte de opplagt at Andreas Faye stod i vegen for dem, for Munch som historiker og for Jørgen Moe som sagnutgiver. Men for oss nå står det klart at ikke bare var Faye en svært habil og kompetent historiker, han var også først med sitt verk Norske Sagn. Som forsker med et etablert internasjonalt nettverk var han åpenbart langt forut for si tid.

Munchs anmeldelse av Norske Sagn var et „,bakholdsangrep”, hevder Bugge Amundsen i den nevnte artikkelen fra 2002. Det at Munch, for øvrig sammen med mange andre, til og med hadde levert materiale til samlinga Norske Sagn, og dessuten hadde lest deler av manuskriptet før publiseringa, gjorde at angrepet kom så overraskende på Faye. Bugge Amundsen mener at Faye var offer for en rein hovedstadskonspirasjon.

Det vi iallfall synes å øyne i denne saka, er at aktører blant hovedstadens intellektuelle, intelligentsiaen og folk ved universitetet, ønska et klarere sentralt 
hegemoni. Arendal og omegn var, som vi har sett, ingen akademisk utkant på denne tida. Det er påfallende at de mer nasjonalt innadvendte i hovedstaden effektivt sørga for - med utgangspunkt i Munchs anmeldelse - å stemple Faye som forskningsmessig inkompetent, og sagnsamlinga hans som stilløs, knusktørr og uinteressant.

Det som var viktig for Faye, var ikke å være dikter, det var ikke det å ha en „nasjonal språkstemme”, men isteden saklig og troverdig å gi materiale til andre, til diktere og andre kunstnere, slik at de kunne utnytte sagna i sin kunst.

Dette ønsket blei da også til overmål oppfylt: Welhaven gjorde straks bruk av Fayes sagn i sine dikt, Ibsen brukte dem gjennomgående i hele sitt forfatterskap, Th. Kittelsen henta inspirasjon derfra til mange av sine tegninger av tusser og troll, nøkk og hulder. Vårt bilde av disse skikkelsene fra norsk folketro har vi nettopp fra Kittelsens tegninger, og han igjen har inspirasjonen fra Fayes sagn. Disse sagna har således vært en uvurderlig kilde for samtidige og seinere kunstnere, akkurat slik Faye ønska at de skulle være. Men om mange kunstnere ofte brukte materiale fra Fayes samling, var det likevel ingen av dem som krediterte han, eller som opplyste hvor de hadde henta sagnstoffet fra. Faye og hans pionerinnsats gikk i allmennheten nesten mot total glemsel.

I dag står det klart som urimelig at P.A. Munchs dom om Fayes Norske Sagn er blitt stående mer eller mindre helt opp til vår tid. Munchs syn blei rundt århundreskiftet sementert av professor Moltke Moe (1859-1913), Jørgen Moes sønn, i hans verk „Det nationale gjennembrud og dets mænd”. Der blei P.A. Munchs anmeldelse av Norske Sagn nærmest kanonisert som den endelige sannhet om Faye som sagnutgiver. (Moe 1927.)

Metoden som blei brukt til å definere bort Faye, var ganske spesiell og kunstig, må en kunne si. Faye blir av Moltke Moe, og seinere av dem som har bygd på han, omtalt metaforisk som ,den første frysende svale”, dvs. den som varsler sommeren, men som sjøl ikke er med når det skjer, når sommeren kommer (Moe 1927: 49). „Sommeren” er da ,,det nasjonale gjennombrudd”, som Moltke Moe isteden knytter til faren, Jørgen Moe, og til Asbjørnsen, i tillegg til P.A. Munch og Ivar Aasen. Men i motsetning til en så kunstig konstruksjon er det avgjort på høy tid nå å slå fast at den som var først, faktisk var først, og at Faye dermed ikke bare hører med $i$,det nasjonale gjennombrudd", men at gjennombruddet naturligvis kom med hans Norske Sagn i 1833, og ikke med Asbjørnsen og Moe ti år seinere.

Faye var fra 1833 sokneprest til Holt ved Tvedestrand. Han kom dermed til Holt samme år som Norske Sagn kom ut. Og fra 1839 underviste han ved og styrte lærerseminaret.

Holt seminar var en foregangsinstitusjon innen høyere utdanning i Norge. Vi kan faktisk se at Faye la avgjørende vekt på internasjonalisering fra starten av. Faye sjøl var såkalt førstelærer ved seminaret. Da annenlærerstillinga ved semi- 
naret blei utlyst våren 1839, meldte det seg hele 27 søkere, 26 av dem var ferdige teologer. Blant søkerne var det folk som seinere blei både stiftprost, biskop og til og med stortingspresident. Men Faye valgte ikke annenlæreren blant dem. Isteden tilsatte han Knud Jørgensen (1810-53). Jørgensen var født i Holt, men minst like viktig, om ikke viktigere, må det ha vært at han etter teologisk embetseksamen hadde reist utenlands og hatt studieopphold i Göttingen, og hadde studert skolevesenet i Preussen og Sachsen (Larsen 1951: 30). Vi ser at når det gjelder internasjonalisering, som først i vår tid er blitt et så viktig instrument for kvalitetssikring innen forskning og høyere utdanning, var Andreas Faye og dermed Holt seminar langt forut for si tid.

Da Ivar Aasen (1813-96) var på sin lange ferd rundt i landet mellom 1842 og 1846 for å studere bygdedialektene, var han rett etter nyttår 1845 ei hel uke sammen med Andreas Faye på Holt. De to diskuterte og samtalte hver dag hele uka. Slik Aasen omtaler disse dagene og samtalene i dagboka si, tyder det på at det var fruktbare tanker og meninger for prosjektet hans som de to mennene utveksla denne uka på Holt i januar 1845. (Aasen 1960: 111, 140.)

Erfaringene fra Holt seminar nedfelte Faye særlig i ei praktisk-pedagogisk bok for lærere, Almueskolen eller Vink til at opdrage og undervise Børn, samt ordne og styre en Almueskole (Faye 1853). Ei slik bok fantes ikke fra før i Norge, og den representerte et betydelig pedagogisk pionerarbeid.

Faye leda og underviste ved Holt seminar til han søkte et roligere kall i Sande i Vestfold, som han tiltrådte i 1860. Han var sliten etter mange års intenst arbeid som prest, seminarbestyrer og forfatter. Men det var med vemod han drog fra Holt seminar, og det var med beklagelse seminarstudentene og de øvrige lærerne så han dra. De fikk da malt et praktfullt portrettet av Faye, som nå eies av UiA. Maleriet blei utført 1861 av Christiane Schreiber (1822-98), en av de fremste norske portrettmalerne i samtida.

I Sande fortsatte Faye å sende ut små og store bøker og skrifter, de fleste innen historie. De viktigste bøkene var Norge $i$ 1814, ei jubileumsbok til 50-årsjubileet for grunnlova, og aktuell igjen i år (2014) ved 200-årsjubileet, og dessuten Christianssands Stifts Bispe- og Stiftshistorie (1867).

I 1864 blei Faye innvalgt som medlem nr. 78 av det da sju år gamle Videnskabsselskabet i Christiania, det som nå er Det Norske Videnskaps-Akademi, og i 1866 blei han utnevnt til Ridder av St. Olavs Orden ,for”, som det heter, „Fortjeneste som Embedsmand og i videnskabelig Henseende". Til tross for disse seine anerkjennelsene fra hovedstaden og Kongen var han for lengst marginalisert fullstendig som folkeminnegransker. Muligens var det derfor på nytt et historieverk, nemlig boka hans om Norge i 1814, som var grunnlaget for innvalget også i Videnskabsselskabet i Kristiania. Faye blei for $\emptyset$ vrig innvalgt der året etter at P.A. Munch døde i Roma.

Andreas Faye døde i Sande 67 år gammel i 1869, og er gravlagt der. 
I dag, som internasjonalisering av forskning og høyere utdanning er grunnleggende og selvsagt, må vi tro tida endelig er kommet til ei total revurdering og oppvurdering av Faye både som forsker generelt og som sagnforsker spesielt. Bugge Amundsens artikkel fra 2002 kan ses på som ei fullstendig faglig rehabilitering av Faye, og den plasserer og definerer han som folkeminnevitenskapens grunnlegger i Norge, vitenskapelig trygt forankra som han var i samtidas internasjonale forskning på feltet.

Da Faye tok avskjed med Holt seminar i 1861, holdt den fremste av de andre lærerne, Andreas Feragen, en tale for han på vegne av studenter og lærere. Der sa han bl.a. dette om og til Faye (Feragen 1904: 70f., språklig modernisert av EHJ):

„Deres valgspråk var: 'Prøv alt, behold det gode'. Dette valgspråk tro la De aldri an på å binde oss i et nett av bestemte regler og forskrifter, for De visste godt, at slikt ville tjene kun til å kue ånden og drepe livet, og ånd og liv ville De jo alltid ha i undervisningen. [---] De sa oss Deres mening om hva De fant best, og la så til: 'Prøv nå, og velg!'. Takk for en slik anerkjennelse av en lærers frihet til å følge egne synsmåter når det gjelder bruk av former og metoder. De ville ikke få oss til å gå i metodikkens strenge ledebånd og advarte mot det stive pedantiske vesen."

Også Fayes pedagogiske ledelse av lærerseminaret var utprega moderne i innhold og form. Universitetet i Agder vil gjøre klokt i å holde arven fra Holt seminars første bestyrer høyt i hevd.

\section{Litteraturliste}

Aasen, I. 1960. Brev og Dagbøker. Band 3: Dagbøker 1830-1896. Ved Reidar Djupedal. Oslo: Det Norske Samlaget.

Amundsen, A.B. 2002. „Fortelling og foredling. Andreas Faye som romantisk sagnfortolker”. I: Amundsen, A.B., Hodne, B. og A. Ohrvik. (red.). Sagnomsust. Fortelling og virkelighet. Oslo: Novus. 26-59.

Askedal, J.O. 2011. „Nicolai Henrich Jæger (1780-1846): Byfogd i Arendal, leksikografisk pioner og naturhistorisk entusiast”. I: Hanisch, T.E. (red.). Agder Vitenskapsakademi Årbok. Kristiansand: Portal forlag. 95-128.

Braadland, J.F. 2004. „Andreas Fayes store sagnsamlingsprosjekt”. I: Bjorvatn, Ø. (red.). Sølvkisten stander i Hanekam. 150 sagn fra Agder, Rogaland og Telemark samlet av Andreas Faye. Tvedestrand: Bokbyen forlag. 9-16.

Eide, E. 2012. „Jacob og Lovise Aalls boksamlinger”. I: Molden, G. (red.). Kunnskap og opplysning - til nytelse og nytte... Artikler fra „opplysningsseminaret”, Nes Verk og Arendal, 9.-10. desember 2011 (= Jacob Aalls-prosjektets skriftserie nr. 7). Tvedestrand: Næs Jernverksmuseum. 41-50.

Faye, A. 1831. Norges Historie til Brug ved Ungdommens Underviisning. Christiania: Trykt paa Forfatterens Forlag hos Johan Krohn.

Faye, A. 1833. Norske Sagn. Arendal: N.C. Halds Bogtrykkerie (2. utgave 1844: Norske FolkeSagn. Christiania: Guldberg and Dzwonkowskis Forlag.) 
Faye, A. 1833b. [Svar på P. A. Munchs anmeldelse av Norske Sagn]. Vidar 67 og 68 for 23. og 30. November.

Faye, A. 1853. Almueskolen eller Vink til at opdrage og undervise Børn, samt ordne og styre en Almueskole. Christiania: Carl C. Werner and Company.

Feragen, A. 1904. Tilbagesyn paa mit liv med et blik paa folkeskolen før og nu. Tillægshefte til Norsk skoletidende. Hamar: Norsk skoletidende bogtrykkeri.

Johansen, N.V. 2012. „Litt rundt etableringen av N. C. Halds Bogtrykkeri”. I: Molden, G. (red.). Kunnskap og opplysning - til nytelse og nytte... Artikler fra „opplysningsseminaret”, Nes Verk og Arendal, 9.-10. desember 2011 (= Jacob Aalls-prosjektets skriftserie nr. 7). Tvedestrand: Næs Jernverksmuseum. 89-97.

Krogvig, A. 1915. Fra det nationale gjennembruds tid. Breve fra Jørgen Moe til P. Chr. Asbjфrnsen og andre. Med en indledning utgit av Anders Krogvig. Kristiania: Aschehoug.

Larsen, O. 1951. Kristiansand larerskole (stiftsseminar) gjennom 100 år 1839-1939. Oslo: Olaf Norlis forlag.

Lindtveit, K. 1961. Andreas Faye. Mannen, tiden og verket. Utrykt hovedoppgave, Universitetet i Oslo, Institutt for nordisk språk og litteratur.

Moe, M. 1927. „Det nationale gjennembrud og dets mænd.” I: Moltke Moes samlede skrifter vol. III, utgitt ved Knut Liest $\varnothing 1$ (=Instituttet for sammenlignende kulturforskning. Serie B: Skrifter IX). Oslo: Aschehoug. 1-196.

Munch, P.A. 1833. [Anmeldelse av] Andreas Faye: Norske Sagn. Vidar 58, 21. September.

Wolff, S.O. 1833. [Kommentar til P. A. Munchs anmeldelse av Andreas Faye: Norske Sagn]. Den vestlandske Tidende 41 og 42, for 19. og 23. November.

\section{Summary}

The University of Agder changed status from a university college to a full-fledged university with all university privileges in 2007 . However, the academic roots of the university go back to the year 1839 , when the first teacher training college was established in Holt in Agder, close to the small town of Tvedestrand. This year (2014), then, the University of Agder can celebrate that the oldest studies at the university are 175 years old. This paper takes a closer look at the man who became the first rector of the college at Holt, the priest Andreas Faye (1802-69). Faye was an extremely active scholar and an important pioneer in several areas - folklore, history and education being perhaps the most important ones. This paper also shows how he, and more than his contemporary Norwegian colleagues, was engaged in an international network of researchers, especially in Denmark and Germany. 